\title{
Integrated Knowledge Acquisition from Text, Previously Solved Cases and Expert Memories
}

Franz Schmalhofer, Otto Kühn, Gabriele Schmidt

Deutsches Forschungszentrum für Künstliche Intelligenz GmbH 


\section{Deutsches Forschungszentrum für Künstliche Intelligenz}

The German Research Center for Artificial Intelligence (Deutsches Forschungszentrum für Künstliche Intelligenz, DFKI) with sites in Kaiserslautern und Saarbrücken is a non-profit organization . It was founded in 1988 by the shareholder companies ADV/Orga, AEG, IBM, Insiders, Fraunhofer Gesellschaft, GMD, Krupp-Atlas, Mannesmann-Kienzle, Nixdorf, Philips and Siemens. Research projects conducted at the DFKI are funded by the German Ministry for Research and Technology, by the shareholder companies, or by other industrial contracts.

The DFKI conducts application-oriented basic research in the field of artificial intelligence and other related subfields of computer science. The overall goal is to construct systems with technical knowledge and common sense which - by using Al methods - implement a problem solution for a selected application area. Currently, there are the following research areas at the DFKI:

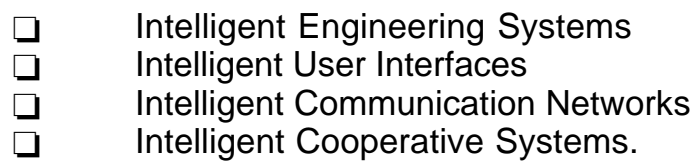

The DFKI strives at making its research results available to the scientific community. There exist many contacts to domestic and foreign research institutions, both in academy and industry. The DFKI hosts technology transfer workshops for shareholders and other interested groups in order to inform about the current state of research.

From its beginning, the DFKI has provided an attractive working environment for Al researchers from Germany and from all over the world. The goal is to have a staff of about 100 researchers at the end of the building-up phase.

Prof. Dr. Gerhard Barth

Director 
Integrated Knowledge Acquisition from Text, Previously Solved Cases, and Expert Memories

Franz Schmalhofer, Otto Kühn, Gabriele Schmidt

DFKI-RR-90-14 
This report is a slightly modified version of the paper which appeared in Boose, J.W. \& Gaines, B.R. (eds) Proceedings of the 5th Banff AAAl Knowledge Acquisition for Knowledge Based Systems Workshop, Nov. 4-9, 1990, p 29-1 to 29-20.

(C) Deutsches Forschungszentrum für Künstliche Intelligenz 1990

This work may not be copied or reproduced in whole or in part for any commercial purpose. Permission to copy in whole or in part without payment of fee is granted for nonprofit educational and research purposes provided that all such whole or partial copies include the following: a notice that such copying is by permission of Deutsches Forschungszentrum für Künstliche Intelligenz, Kaiserslautern, Federal Republic of Germany; an acknowledgement of the authors and individual contributors to the work; all applicable portions of this copyright notice. Copying, reproducing, or republishing for any other purpose shall require a licence with payment of fee to Deutsches Forschungszentrum für Künstliche Intelligenz. 


\title{
Integrated Knowledge Acquisition from Text, Previously Solved Cases, and Expert Memories
}

\author{
Franz Schmalhofer, Otto Kühn, Gabriele Schmidt \\ German Research Center for Artificial Intelligence \\ University Bldg 57 \\ Erwin-Schrödinger Str. \\ D-6750 Kaiserslautern \\ Germany \\ e-mail: schmalho@informatik.uni-kl.de
}

\begin{abstract}
Within the model-based knowledge engineering framework, an integrated knowledge acquisition method was developed for a complex real-world domain with different traces of expertise. By having an expert constructively explain the previously solved cases with more general information from other traces of expertise (text, expert memories) a model-centered knowledge base is constructed. The proposed method allows for an early knowledge verification where the relevance, sufficiency, redundancy, and consistency of knowledge are already assessed at an informal level. The early knowledge verification efficiently prepares the consecutive knowledge formalization. Through a cognitively adequate model of expertise and the explanation-oriented knowledge elicitation procedures, user friendly second generation expert systems may be developed.
\end{abstract}

Within the last decade, knowledge acquisition has emerged as an important area in expert system development. Whereas some researchers concentrated on the investigation of knowledge elicitation methods (Boose \& Bradshaw; 1987; Diederich, Linster, Ruhmann \& Uthmann,1987), others have emphasized the importance of developing appropriate models of expertise (Clancey, 1985; Chandrasekaran, 1986, Breuker \& Wielinga, 1989). Obviously, a complete knowledge acquisition technique must include both, the formation of a model of expertise, as well as the elicitation of corresponding knowledge.

Through the knowledge elicitation research various methods for interviewing humans and probing their expertise have been imported from the behavioral sciences (Hoffman, 1989) and their usefulness for the development of expert systems was investigated. The development and application of respective tools has shown, how repertory grids, thinkaloud methods, scaling techniques, or having the expert perform special tasks (and other data collection and analysis procedures) can be utilized for knowledge elicitation.

Research on model-based knowledge engineering has produced a number of principles and a systematics on how models of expertise can be formed or selected from a library of models. Problem classes (Clancey, 1985), generic tasks (Chandrasekaran, 1986) and interpretation models (Breuker \& Wielinga, 1989) are somewhat different but similar incarnations of models of expertise.

In order to develop a successful expert system for a complex real world application, such as computer aided planning, model-based knowledge engineering must be coordinated with appropriate knowledge elicitation procedures. Without a model of expertise, a knowledge engineer would be overwhelmed by the mass of unorganized entities which must be dealt with during knowledge acquisition. Without appropriate knowledge elicitation tools, establishing a complete knowledge base would be too time consuming. For the desired coordination, which should already be performed in the domain definition phase (Woodward, 1990), the knowledge engineer must consequently deal with the following three problems: 
1) A good model of expertise must be found or developed. For the purpose of the present paper it is not critical which specific modeling approach is selected (Karbach, Linster \& Voss, 1990), but only that the knowledge acquisition is model-based, i.e. that a model of expertise is used which is basically adequate for the desired application. Such a model may be obtained by selecting it from a library of models (Breuker \& Wielinga, 1989) or by constructing it, for instance through an ontological analysis (Alexander, Freiling, Shulman, Rehfuss \& Messick, 1987).

2) Traces of expertise which serve as sources of information must be found and adequate knowledge elicitation procedures and tools must be developed so that knowledge can be efficiently elicited. Such tools may also attempt to elicit implicit knowledge (Lewandowski, Dunn, \& Kirsner, 1989), which experts cannot directly verbalize.

3) Finally, the knowledge elicitation must be coordinated with the specifically selected model of expertise, so that the elicited knowledge appropriately supplements the model. In complex real world domains, a number of different traces of expertise will exist. Some traces of expertise may be generally accessible but incomplete, others may be confidential within some community and possibly contradictory between different competing communities. Therefore, it is quite critical to develop or select a model, so that the knowledge details required for some model can indeed be supplied.

In the current research, an integrated knowledge acquisition method is developed and applied. First, a description of the application domain, resulting from an analysis of historical, sociological and cognitive aspects will be presented. Then the proposed method, which is centered around the model of expertise and uses explanation-oriented knowledge elicitation procedures, is described. Finally, the results of a pilot application of the method will be reported and discussed (sections 3. and 4.).

\section{ANALYSIS OF MECHANICAL ENGINEERING KNOWLEDGE}

Our knowledge acquisition approach is part of the ARC-TEC-project (ARC-TEC stands for Acquisition, Representation and Compilation of TEChnical Knowledge; Richter, Boley \& Wetter 1989). The application domain of the project is mechanical engineering and Computer-Integrated Manufacturing (CIM) where knowledge-based product models (Legleitner, 1990) are to be shared among different tasks (Bullinger \& Salzer; 1989). However, for the purposes of the current paper, only Computer Aided Planning (CAP) for the manufacturing of workpieces (Thien-Chien \& Wysk, 1985) and more specifically the manufacturing of rotational parts will be considered.

Rotational parts or workpieces are manufactured by putting some more or
less cylindric piece of metal (mold) into the fixture (i.e. chucking) of a
manufacturing machine (CNC machine). The chucking fixture together with
the attached mold is then rotated at a relatively high speed, with the
longitudinal axis of the cylinder as the rotation center. The rotational axis and
all movements of a specific cutting tool (movements which perform a cut as
well as movements which only position the tool) lie in a plane. While the
chucking fixture and the attached mold are rotated, a cutting tool moves along
some contour. Thereby the desired geometric shape of the workpiece is
obtained. As a result of this processing, axle shafts, drive shafts, or bevel
wheels may be produced.
The technique of manufacturing a rotational part may be better understood by
a comparison to pottery. The manufacturing processes are similar to making a
pot in the following way: One puts or attaches a piece of clay to a potter's
wheel and shapes the clay to a specific form, only by removing some parts of
the clay while the potter's wheel is turned ${ }^{1}$. Contrary to the soft clay, which
also allows a potter to push some material to a neighboring position, a

${ }^{1}$ This analogy was pointed out by Harold Boley 
rotational part or workpiece (metals) is shaped, solely by removing materials with a hard cutting tool.

Figure 1 shows a graphical representation of a (partial) workplan for a rotational part. The geometric form of the mold and the target workpiece are overlaid. The specific chucking fixture is shown and the sequence of cuts is specified. For a complete workplan additional specifications are needed such as the cutting tools used.

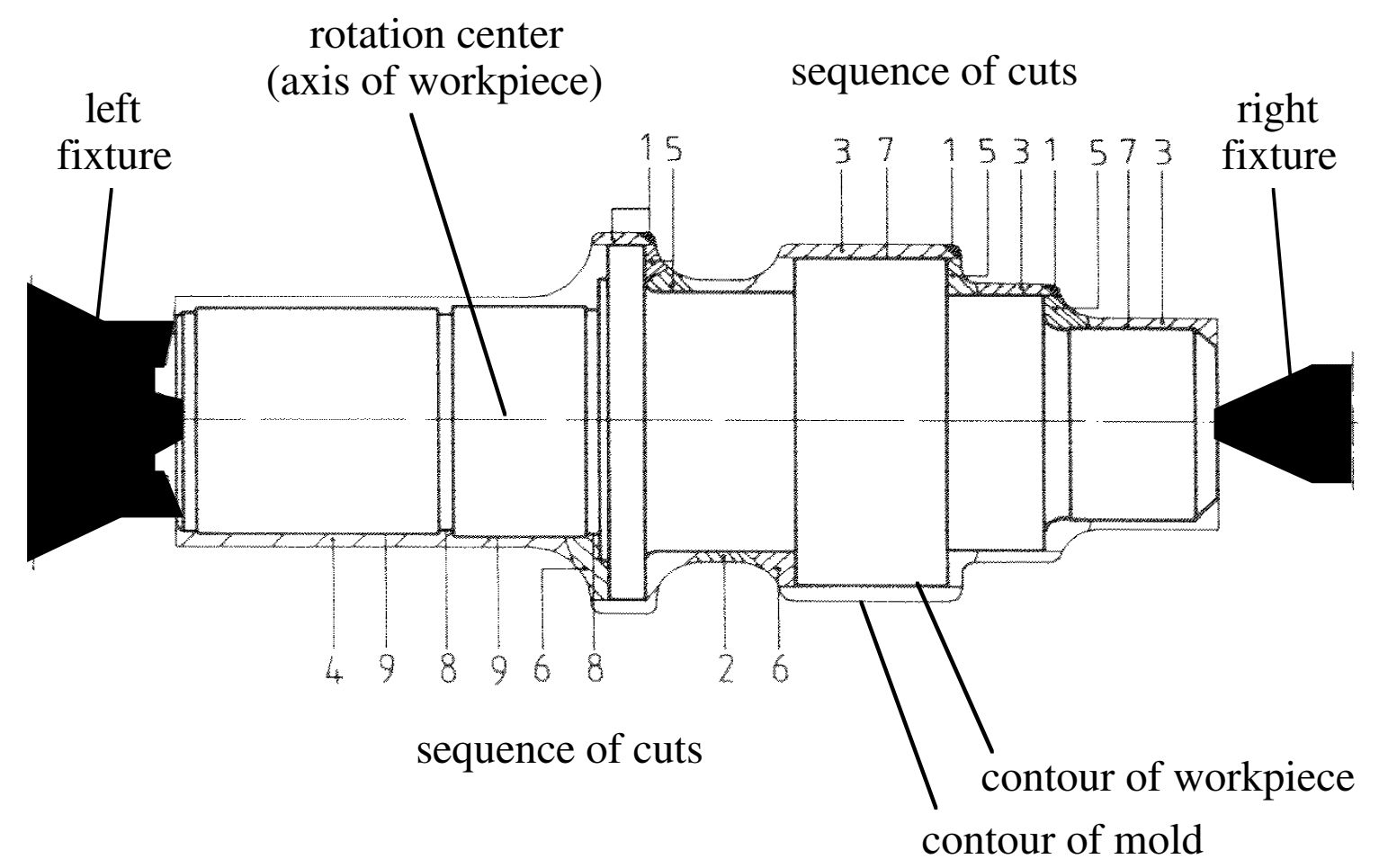

Figure 1: Graphical representation of a simplified workplan for a rotational part (after: Example for application, SPK-Feldmühle Werkzeuge, undated)

While the principles of manufacturing a rotational part may be simple, the actual manufacturing process and consequently also the respective planning task is extremely complex. The complexity arises from the large number of different possibilities for an operation and the various dependencies among different operations. An additional complexity in the planning process originates from the large body of modern technologies, accumulated scientific knowledge and various practical experiences, which can be applied for improving or even optimizing the manufacturing process. Therefore production planning is knowledge intensive. Especially, for this domain the development of expert systems is consequently a promising endeavor (Richter, 1990; Pfeiffer, Siepmann \& Teichmann, 1988).

\subsection{Historical, Sociological and Cognitive Aspects (HISOCO-Analysis)}

The following results show that a historical assessment of an application domain can reveal the traces of expertise that have been established and are more or less readily available in an area (compare to Gaines, 1989). A related analysis of sociological factors determines where traces of expertise can be found, which traces are publicly available and which traces are treated confidentially for example within a company. Cognitive analyses of human expertise indicate how planning problems are solved in practice and which requirements must be met by the expert system and the elicitation methods in order to be cognitively adequate. Such a combined analysis of the historical, sociological and cognitive aspects of expertise in some application domain is termed HISOCO-Analysis (Fischer \& Schmalhofer, 1990). 
Historically, mechanical engineering originated from craftsmanship. Over a time period of several centuries, craftsmanship (the competence of the community of craftsmen) developed into a differentiated set of specialized skills, which are now distributed among a number of different people with various educational backgrounds. In addition to the practical skills of manufacturing and efficiently preparing the manufacturing process (design of workpiece, workplanning etc), polytechnical research has provided a more general and theoretically oriented understanding. Today, practical skills as well as theoretical knowledge are two different types of expertise in mechanical engineering (Spur, 1979; Fandel, Dyckhoff \& Reese, 1990).

The sociological analysis revealed the following aspects: Whereas the results of theoretical research are frequently published and therefore generally accessible, the more practical skills are often confidential although they may be individually communicated in apprenticeships (Brödner 1985; Spur, 1979). Highly skilled practitioners, who earn a living with their practical skills, would create additional competition for themselves by widely distributing the specific tricks of their trade. Practical skills are therefore often idiosyncratic to a person or a company. Theoreticians, on the other hand, who are not directly interested in practicing engineering themselves, further their reputation when their results are published. Since theoretical results are published and discussed in a larger community, they are more explicitly presented, more generally accepted and in themselves more consistently denoted.

Cognitive analyses show that people form libraries of experiences from previously solved cases (de Groot, 1966; Shaw \& Woodward, 1989; Schmalhofer \& Wetter, 1988; Strube \& Janetzko, 1990; Weber, 1988; Riesbeck \& Schank, 1989). A practitioner's memory usually contains a large number of experiences which are hierarchically structured (Chase \& Ericcson, 1982). Therefore it comes to no surprise that adapting previous solutions to newly arising situations (modification planning) is a frequently used planning procedure in mechanical engineering (Thoben \& Schmalhofer, 1990).

As the HISOCO-Analysis has shown, the activities of practitioners and theoreticians yield different traces of expertise which can be utilized for knowledge acquisition:

1) Theoreticians are usually concerned with general rules. The general knowledge which renowned theoreticians accumulated in their research can be found in various text books.

2) The specific solutions which practitioners have found over a number of years are stored in the filing cabinets or databases of companies. Sometimes records of previously solved cases have also been published (e.g. Example for application, SPK-Feldmühle Werkzeuge, undated).

3) Through their possibly implicit expert memories, which they have acquired over a number of years (de Groot, 1966), practitioners may possess an expert classification for the various types of workpieces. These expert memories may be tapped with appropriate knowledge elicitation techniques.

Figure 2 shows an illustration of the three identified traces of expertise. These traces of expertise may partially complement one another. Consequently, a more complete and qualitatively better knowledge base may be constructed with an integrated knowledge acquisition method which combines different traces of expertise than with isolated knowledge acquisition procedures. 


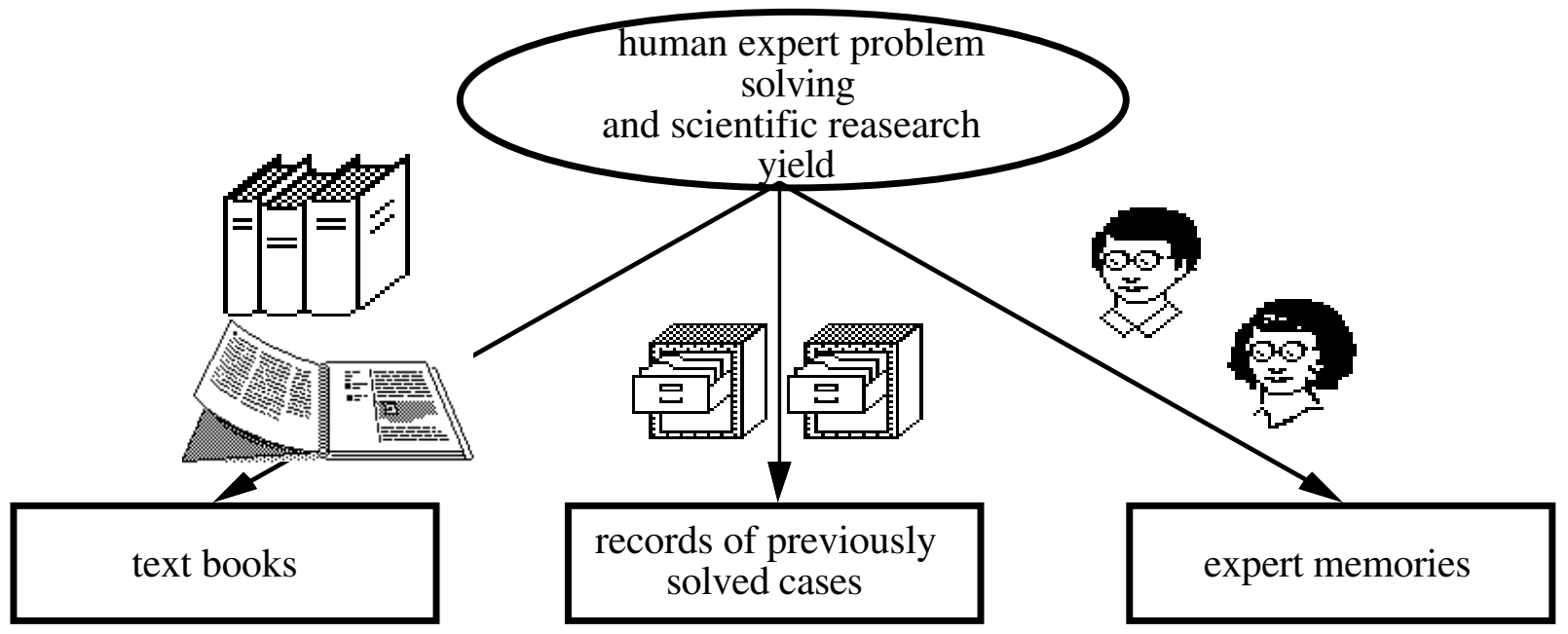

Figure 2: Traces of expertise

\subsection{Model of Expertise for Production Planning}

The results of the cognitive analysis were also used to specify a high level model of expertise for the desired application, which is shown in Figure 3. By building such a model on a cognitive foundation, a cognitively adequate expert system may be developed which will meet a higher acceptability in the professional community of the application domain (Schmalhofer, 1987). In addition, a cognitively adequate model also facilitates the verification of knowledge in the elicitation phase: When the elicited knowledge is classified according to the way of thinking in the specific application domain, the expert can easily verify the acquired knowledge.

In an empirical investigation of the three diffreent types of production planning, namely replication planning, modification planning and planning from scratch (Thoben \& Schmalhofer, 1990), and a detailed think-aloud study of planning from scratch (Schmidt, Legleitner \& Schmalhofer, 1990), the expert's problem solving behavior for finding a production plan was investigated in detail. The results showed that all production planning can be seen as modification planning, i.e. a more or less abstract skeletal plan (Friedland \& Iwasaki, 1985; Chien, 1989) is retrieved and subsequently refined to a specific workplan. When the skeletal plan is quite general, skeletal plan refinement, which relies on generative planning processes, plays the major role. When the skeletal plan is so specific that it is very close to a detailed production plan, the memory retrieval accomplishes the planning goal (replication planning). Replication planning is thus a special case of modification planning, where a complete plan is already available. Between these two extremes the various forms of modification planning occur, where the planning effort is differently distributed between the retrieval of the skeletal plan and its refinement. In addition, the planning processes take into consideration the resources of the factory (e.g. availability of specific machines and tools) in which the workpiece is to be manufactured.

The abstract types of processing in the resulting model of expertise which are shown in Figure 3 can be described in the following way: The problem of production planning consists in finding an adequate production plan for a given workpiece which is to be manufactured in some given factory. In mechanical engineering the collections of the wortkpiece and factory data are usually termed workpiece model and factory model. From these concrete data an abstract feature description of the workpiece and an abstract context specification are obtained through the application of abstraction or classification rules. To these abstract workpiece and context descriptions a skeletal plan can be associated which may be seen as an abstraction of a concrete production plan (Bergmann, 1990). The skeletal plan is then refined with the help of the concrete workpiece and the factory data so that an executable production plan is obtained. 


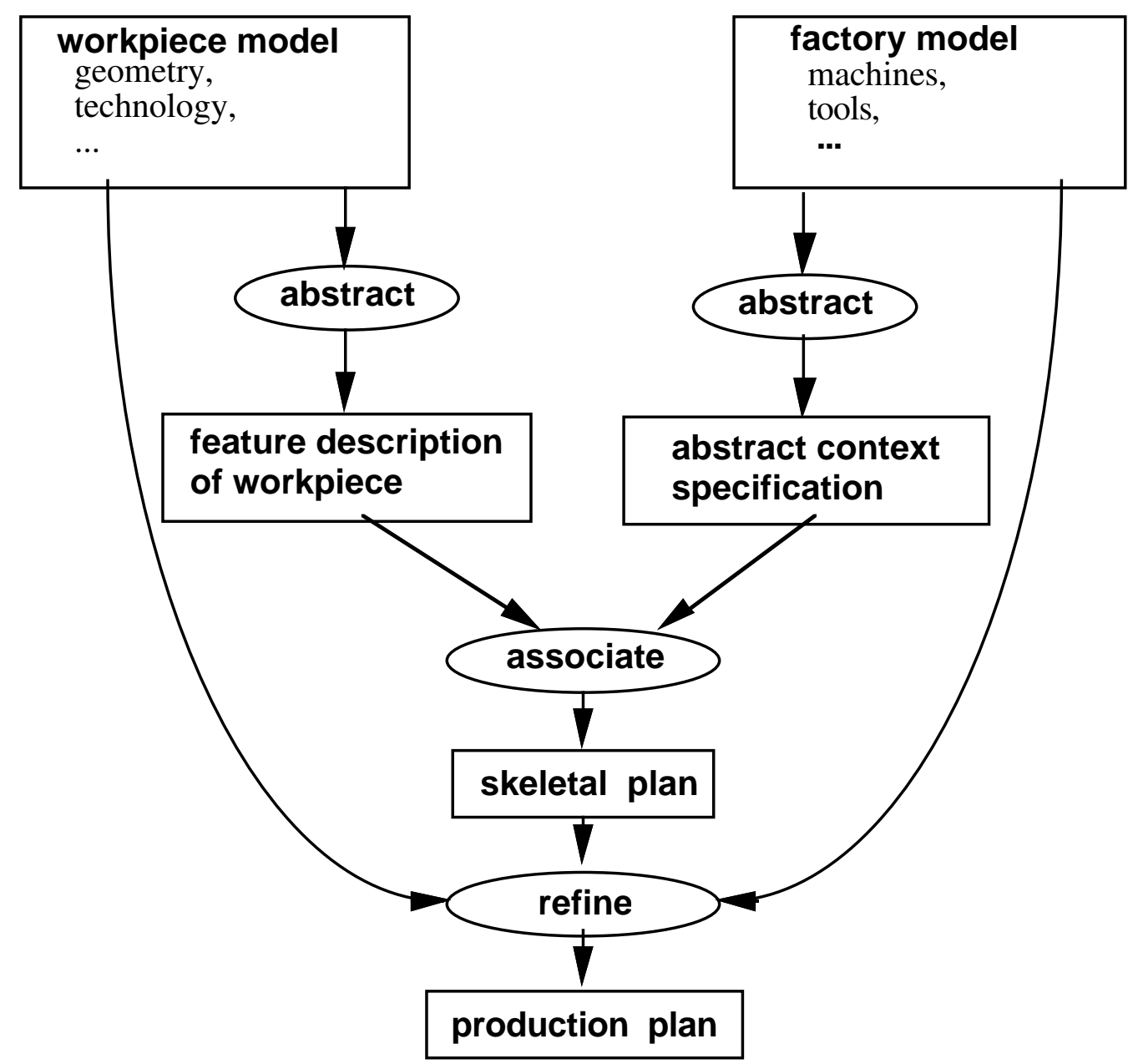

Figure 3: Model of expertise for production planning

Supposedly an expert's memories include a hierarchy of workpiece classes. Results from cognition (Chi, Feltovich \& Glaser, 1981; Egan \& Schwartz, 1979; Glaser \& Chi, 1988, de Groot, 1966; Chase \& Ericcson, 1982) provide substantial evidence that these classes have been formed according to skeletal production plans.

In our knowledge acquisition method, the model of expertise of Figure 3 is used for immediately classifying each knowledge unit into the different categories provided by the model. A knowledge unit may for example consist of some elicited rule or schema, which is expressed in natural language. The categories of the model are determined through the different abstract types of processing (i.e. abstract, associate, refine) which occurr in the model of expertise.

Because of the high complexity of the domain, a domain-specific decomposition of the task into a small number of canonical subtasks was furthermore introduced. Thereby the domain-specific knowledge can be adequately structured (Wachsmuth, 1987). The cognitive analysis showed that production planning for rotational parts can be subdivided into the subtasks of 1) finding a chucking fixture, 2) determining the sequence of cuts, and 3) selecting appropriate cutting tools. Through this additional subdivision of each category of the model of expertise, one obtains knowledge classes with a reasonable number of knowledge units. These sizeable categories facilitate knowledge acquisition. This is particularly important when knowledge is to be elicited from several traces of expertise. The sizable categories furthermore provide a possibility for structured mapping (Bylander \& Johnson, 1989). 


\section{DESCRIPTION OF INTEGRATED KNOWLEDGE ACQUISITION}

When new or additional information (or knowledge) is to be inserted to an already existing knowledge base or some model of expertise, the new information needs to be adjusted to the givens of the existing structure. This process may be generally called knowledge assimilation (Lefkowitz \& Lesser, 1987).

On the other hand, when knowledge is independently acquired from different but equally respectable sources (e.g. different experts, different traces of expertise, etc.) or with different and equally profitable tools, knowledge may be integratively analyzed. Thereby, a single uniform knowledge base can be produced. Such a merging of knowledge may be termed integrated knowledge acquisition (Brazdil \& Torgo; 1990; Morik, 1989). Although aspects of knowledge assimilation are also relevant for this paper (e.g. in the insertion of the elicited knowledge into the model of expertise), its focus lies in the integration of knowledge from different sources.

\subsection{General Problems}

When several profitable traces of expertise have been identified, an integrated knowledge acquisition can accomplish an efficient utilization of the different traces and an early verification of the elicited knowledge. Usually, these traces will contain overlapping information. By itself none of the traces will provide all the relevant information. However, the combination of several traces together with the model of expertise may be sufficient. Firthermore, the information obtained from different sources may appear or actually be contradictory. Consequently, an integrated knowledge acquisition method must address the following problems:

1. Are there parts of an information source which can be described as redundant or contradictory with respect to other knowledge and how can such redundancies and contradictions be eliminated?

2. Which information is relevant for solving the target problems and which information is in addition needed for the combined information to be sufficient?

The general problem of integrated knowledge acquisition thus consists of finding a set of knowledge units which is sufficient for performing the target tasks. In addition, the set of units should not be arbitrarily redundant, i. e. it should satisfy some weak minimality requirements.

From a formal point of view, it is well understood that in general the specified problems are intractable if not undecidable. From a practical point of view, it is equally obvious that the specified problems must be treated in a sophisticated manner, so that at least humans can eliminate major contradictions and undesirable redundancies (with the assistance of computer tools).

\subsection{Basic Principles}

At first, the principles for assessing the relevance and sufficiency of knowledge will be introduced. Secondly, the principles for eliminating contractions and undesirable redundancies will be discussed. Consequently, it will be shown how the application of these principles yields an early knowledge verification.

2.2.1. Relevance and sufficiency assessment: The relevance and the sufficiency of general knowledge units can be determined by having an expert explain prototypical target tasks (cases) with the general knowledge units. These units (e.g. general statements from a text or general experiences from human experts) are elicited, because of their great generality and high reliability. High quality task solutions are selected, so that the specific set of examples somehow forms a base for all the problems which the expert system is supposed to solve. Because the set of examples defines the particular area of competence of the expert system, these examples can be used as a guide for selecting those general knowledge units which constitute the relevant knowledge. By having the expert instantiate the general knowledge with respect to the specific cases and by performing constructive 
explanations, a bridge is built between the general knowledge units and the specific cases. Thereby a knowledge integration can be performed between a case base and a text, or a case base and general expert experiences. Relevance and sufficiency are consequently assessed with respect to the selected cases.

2.2.2. Elimination of redundancies and contradictions: In order to eliminate major redundancies and overt contradictions the various knowledge units must be compared in a systematic way. The model of expertise together with the domain oriented decomposition into subtasks provides a useful categorization for the elicited knowledge units. By comparing the knowledge units of a category with all other knowledge units of the category the most critical redundancies and contradictions can be detected and eliminated.

2.2.3. Early knowledge verification: Through the application of these principles an early knowledge verification is performed. With informally presented knowledge (e.g. natural language sentences and rules), which is often more comprehensible to a human expert (Schmidt \& Wetter; 1989) relevance, sufficiency, redundancies and contradictions can be identified relatively soon. Formal considerations (i.e. completeness and consistency of knowledge base) are thereby already treated with informally denoted knowledge. Performing such formal considerations at an the informal level is termed early knowledge verification.

\subsection{Acquisition Method}

The proposed integrated knowledge acquisition method basically consists of four episodes, which can be flexibly interspersed. Whereas the first three episodes (1. explanation of solved cases, 2. comparison of similar or related knowledge units, 3. competence delineation) concern the elicitation and analysis of knowledge at an informal level, the forth episode is concerned with the formalization of that knowledge (4. formalization phase). The first three phases will be described in some detail while the formalization phase will be only outlined. An overview of the acquisition method is presented in Figure 4.

2.3.1. Explanation Episode: In this phase, information which is relatively general and supposedly relevant for the target tasks of the future knowledge based system is selected from one or several appropriate sources. Independent from this selection of general information, a set of prototypical previously solved cases is determined. Other than through the desired competence of the future expert system, the general information and the set of cases are selected independently from one another, so that the two information sources can confirm each other. This is of crucial importance for an early knowledge verification.

In the explanation episode, the major task for the domain expert consists in applying the selected general information to the previously solved cases by explaining these cases according to the structure of the model of expertise. When the model of expertise exceeds some degree of complexity, it is desirable (or inevitable) to decompose the explanation task into a number of explanation subtasks (Simon, 1981). For each explanation subtask a different information source may be used and the combination of the different explanation subtasks should be overlapping. For instance, with the described model of expertise (see Figure 3) an expert's general memories about the specific problem classes in the domain may be used for the subtask of defining abstraction rules by explaining the various problem classes (Bergmann \& Schmalhofer; 1990). Additionally, theoretical knowledge from text books may be mainly used for the subtasks of finding the associate and refine rules (Schmidt \& Schmalhofer; 1990). Through the model-oriented explanation of each case, the completeness of the general information with respect to the specific case is established, and it is assimilated to the model of expertise.

In order to further facilitate the examination of the sufficiency of the elicited knowledge and its assimilation to the model of expertise, each elicited knowledge unit is put into a specific form (e.g. an IF- THEN form may be used, when a formal rule base is to be established later on). Since the model of expertise has been constructed to be cognitively adequate, the human expert should feel comfortable in using this structure for generating explanations. 


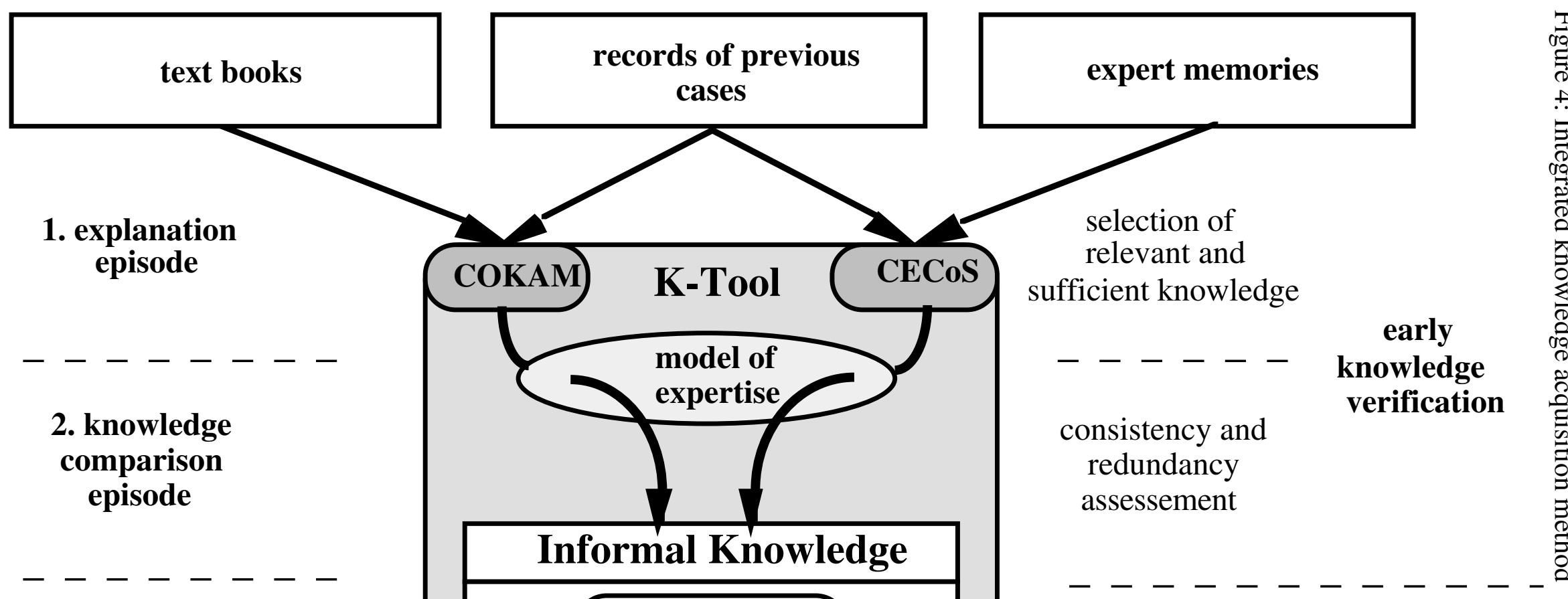

\section{3. competence delineation episode}

collection of

knowledge unit

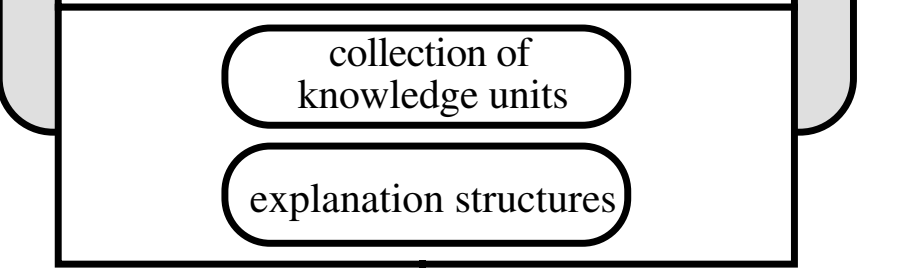

consecutive

knowledge extensions documentation

of translation of knowledge units - - - - formal verification knowledge formalization 
2.3.2. Knowledge Comparison Episode: After two or more cases have been explained, the knowledge units in the different categories of the model can be compared to one another. During this comparison, some knowledge units may be found to be redundant, others may be found to be generalizable, still others may require a differentiation. If a contradiction is found, one or several explanations may have to be revised. This may result in an elimination or adjustment of some knowledge units. The number of times a knowledge unit is used in different explanations can be determined. Each knowledge unit is stated as general as possible and as specific as necessary so that all cases can be explained.

2.3.3. Competence Delineation Episode: In this episode the possible competence which is inherent in the already established (informal) knowledge base is to be delineated. In a most conservative assessment, it is noted that the acquired knowledge is sufficient for successfully solving those problems which were used for knowledge elicitation. In particular, if these solutions were removed from the knowledge base, the respective problems could still be solved by appropriately combining the stored knowledge units. One such combination is the explanation structure which the expert generated and which is stored as part of the informal knowledge base. The knowledge base can thus be used to solve problems by regenerating previous solutions (e.g. for replication planning).

The acquired knowledge may in addition be used to solve problems which at some level of generality are structurally identical to the prototypical problems used in the knowledge acquisition phase. This can be accomplished by following a stored explanation structure. Thereby the general knowledge units are appropriately instantiated with respect to the actual problem, which may be more or less similar to the previously considered prototypical cases. The knowledge base can thus also be used to solve problems by adapting previous solutions (e. g. for modification planning).

By decomposing the expert's explanation structures into meaningful segments, solution methods for various subtasks may be identified. By combining solution methods from the different previously treated problems, solutions to structurally new problems may be created (e.g. for novel planning tasks).

The largest possible area of competence which is based on the acquired knowledge may be delineated by applying the knowledge units in the most general way and by combining the knowledge units in all possible ways. For obvious reasons, for the largest possible area of competence only a rough and pragmatically oriented assessment may be even attempted.

The described competence delineation allows to determine whether iterations of the previously performed knowledge acquisition episodes should be performed or whether the knowledge base already satisfies the customer's requirements (i.e. the requirements of the intended user of the expert system).

2.3.4. Formalization Episode: In the formalization episode, each knowledge unit is translated into its respective formal representation and stored in the formal knowledge base. Thereafter the previously informal explanations are formally examined by traversing the stored explanation structures, this time however with the formalized knowledge units. For those explanation structures, which can be successfully traversed, the early knowledge verification is formally verified. Unsuccessful traversals indicate a bug in the execution of the knowledge acquisition, e. g. insufficiencies in the informal knowledge base, errors in the translation from the informal to the formal knowledge units, etc.

\subsection{Case-Oriented Knowledge Elicitation with COKAM and CECoS}

For an integrated knowledge acquisition, knowledge elicitation tools or procedures (Jacobson \& Freiling, 1989) are required which select the relevant information from the various traces of expertise. COKAM and CECoS are such knowledge elicitation tools or procedures, each performing a joint elicitation from two traces of expertise. COKAM performs a knowledge acquisition from texts, which is enriched by utilizing records of solved cases. With CECoS previously recorded problem solutions are combined with an expert's high level understanding of the global structure of a task domain. Both procedures 
can be applied to perform the explanation episode of the integrated knowledge acquisition. Basically each procedure consists of two phases, a selection and an application phase. In the selection phase, it is first determined which sample of a trace of expertise is to be elicited before the respective elicitation is conducted. In the application phase an explanation task is to be performed which jointly utilizes both traces of expertise. The application phase yields the informal knowledge. Figure 4 indicates the role of COKAM and CECoS within the proposed integrated knowledge acquisition framework. A brief characterization of COKAM and CECoS will be presented next.

COKAM: In the selection phase of COKAM an expert selects texts and text segments which in his or her opinion contain relevant information for performing the target tasks of the future expert system. Independent of the expert's selection of text, the knowledge engineer selects previously solved cases from a filing cabinet or a data base. In the application phase the expert explains each case with the help of the selected text segments and his common sense knowledge. The common sense knowledge is thereby used to fill the information gaps in the collection of text segments. In a previous application, COKAM was used to elicit knowledge without a model of expertise (Schmidt \& Schmalhofer, 1990). However, the integrated knowledge acquisition method requires that the elicited knowledge is categorized according to the model of expertise. This is accomplished with the extended version $\mathrm{COKAM}^{+}$.

CECoS: In the second step of the selection phase, CECoS performs a hierarchical classification of problem classes by eliciting global judgements from human experts. For example, after a complete paired comparison of the cases has been performed by the expert, a hierarchical order of problem classes may be obtained by a hierarchical cluster analysis. In the application phase, the expert has to generate appropriate feature descriptions for each class, so that he can explain the various class memberships of the cases and the different class subsumptions. When CECoS is applied together with COKAM, the same cases should be used.

\section{FIRST RESULTS OF A PILOT APPLICATION}

Naturally, knowledge acquisition in a complex real world domain is more demanding and more time consuming than in a limited test domains such as the blocks world. Nevertheless, it is important to assess the usefulness of the developed method relatively soon. Therefore, a pilot application was performed, so that some critical aspects of the proposed knowledge acquisition method could be evaluated. In particular, it was investigated how willingly experts would relate general statements of expertise (text, memories) to specific cases by generating explanations. Secondly, it was determined, whether the sufficiency and relevance of the elicited knowledge could be judged by early knowledge verification. In addition, it was tested whether appropriate explanation structures could be elicited with COKAM and CECoS and whether the identified knowledge units could be assimilated to the model of expertise.

The two knowledge elicitation procedures COKAM and CECoS are currently being implemented. Preliminary implementations and paper and pencil surrogates were used to perform the pilot application. For these tests, five work pieces with their corresponding workplans were selected from a catalogue (see Figure 1). The technical drawings of the selected shafts served as a graphical representation of the respective product models. A graphical representation was also used for the workplans which showed the workpiece overlaid with the mold, the used chucking fixture and the sequence of cuts.

\subsection{COKAM}

Since the task of explaining the whole workplan is rather complex, the pilot application of COKAM was limited to the elicitation of the knowledge which is relevant for the selection of a chucking tool. The text which was used as one trace of expertise described the different chucking tools which are available and the criteria for the selection of an appropriate 
chucking tool. The expert had no problems identifying text segments which he considered to contain relevant knowledge units. The identified text segments were decontextualized, i.e. references to previous text were resolved so that independent knowledge units were obtained for the informal knowledge base (anaphora resolution). The following items are examples of such knowledge units ${ }^{2}$ :

\section{For long workpieces two chucking fixations are necessary.}

2. When an axial chucking is used for long workpieces, the workpiece may buckle.

3.1.1. Explanation of solved cases: In COKAM, the expert was to explain a particular case by using the identified knowledge units as far as possible. It was found that the knowledge units from the text were not sufficient to explain the solutions of the particular cases, e.g. why lathe center chucking was used for the manufacturing of a specific axle shaft. A complete explanation could be obtained, however, by the addition of some common sense knowledge units such as:

\section{Center holes are possible, when smooth vertical planes on the two ends of the workpiece are not required.}

These units of common sense knowledge were also added to the informal knowledge base. It was found that for subsequent cases less and less common sense knowledge units had to be added. A limited number of knowledge units thus appears to be sufficient for the explanation of a large number of cases. Some of the knowledge units which were extracted from the text were not used in any of the five explanations. The expert deliberated that these units were subsumed by others or were of no use for the specific type of problem, i.e. selection of chucking tools. Using knowledge units from a text in order to explain individual cases apparently constitutes a good means for testing the relevance and sufficiency at an informal level.

3.1.2. Assimilation of the knowledge units into the model of expertise: The elements of the informal knowledge base were then assigned to the categories in the model of expertise. The knowledge unit 1 . is a typical association rule, since it relates a feature of the workpiece (long) to a feature of the workplan (two chucking fixations). The knowledge unit 3. constitutes a common sense explanation given by the expert. Since it relates one feature of the workpiece (smooth vertical planes on the two ends of the workpiece are not required) to another one (center holes are possible) from which consequences for the workplan can be derived more easily, it can be classified as an abstraction rule.

A categorization of the remaining knowledge unit is not so obvious. For the knowledge unit 2. problems arise, since it contains two premises one of which refers to a feature of the workpiece whereas the other refers to a feature of the workplan. Furthermore, the conclusion (the workpiece may buckle) is only a warning which must be taken into account in the planning process. Further analysis revealed that this knowledge unit constitutes a refinement rule. It can be reformulated as:

2a. If an axial chucking is suggested by the skeletal plan and the workpiece is long, then the other parameters of the workplan (e.g. chucking power) must be determined in such a way that the workpiece does not buckle.

This reformulation makes obvious, how unit 2. is understood by the expert. Statement 2a. makes explicit some of the knowledge which had been compiled out in statement 2 . (Anderson, 1983). In other words, the knowledge of statement $2 \mathrm{a}$ is implicitly contained in statement 2.

In order to avoid such problems with the categorization of the knowledge units, the knowledge elicitation procedure COKAM was modified. The modified version $\mathrm{COKAM}^{+}$ differs from the original version in that the expert is told to use the model of expertise as a guideline when generating explanations for the individual cases.

${ }^{2}$ The following items are translations of the original German sentences. 


\subsection{CECoS}

For a first test, the same five cases were used as in the pilot application of COKAM. All possible pairs were randomly presented on the screen. For eachj pair the mechanical engineer (expert) had to assess the similarity of the respective production plans. The similarity was indicated on a seven point rating scale. With the $n *(n-1) / 2=10$ collected similarity ratings a hierarchical cluster analysis was performed. The resulting tree is shown in Figure 5. Through this tree an initial hierarchy of production classes for product models is established, where each nonterminal node indicates a class. The terminal nodes stand for the prototypical members of the class.

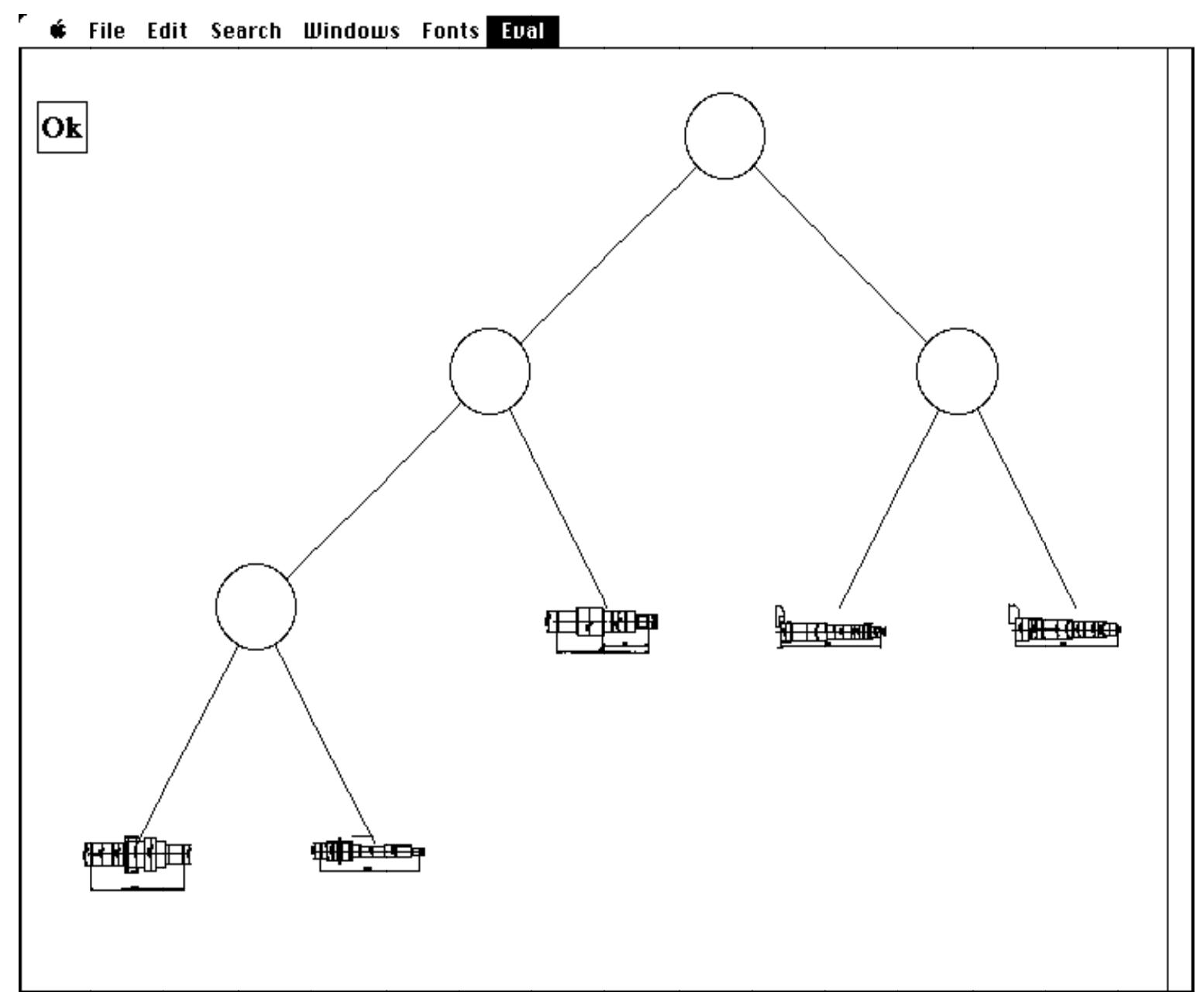

Figure 5: Hierarchy of production classes

3.2.1. Explanation of production class hierarchy: The generated class hierarchy was explained in the application phase of CECoS. For each class of the hierarchy the expert was to name characteristic features which all workpieces in the respective class have in common. The named features should then be defined in terms of the data given in the workpiece (or factory ) model.

For example, the following features were generated by the expert:

1. workpiece of medium size

2. monotonic contour of workpiece

3. workpiece behaves stable during production

4. two chucking fixations necessary

5. can be manufactured with low cutting speed only

Some features like 1. and 2. were defined rather readily, because they can be easily related to geometry or technology primitives of the workpiece model. A workpiece of medium size, 
for example, was defined as a workpiece with a length of 70 to 800 millimeters and a maximal diameter of 10 to 300 millimeters.

Features which referred to the mechanical properties of the workpiece during the production process were more difficult to define. For example, the feature 3 . had to be defined by a relatively complicated combination of terms such as length of workpiece, minimal diameter of workpiece and material of workpiece.

Features 4. and 5. directly refer to a possible manufacturing plan of the workpiece. The expert had some difficulties defining them in terms of the workpiece model.

3.2.2. Assimilation of the defined features into the model of expertise: The definitions for the features 1. to 3. are typical abstraction rules which relate workpiece data to more abstract workpiece features. Knowledge of this category is typically obtained by applying CECoS. According to the model of expertise, the features 4. and 5., which are workplan features, should not be directly related to workpiece data. Instead they should be associated with workpiece features which are abstracted from workpiece data. This assumption fits well to the observation that the expert could only define these features in terms of the workpiece model after performing COKAM. For example, the feature 4 . is associated with a workpiece feature by knowledge unit 1. elicited by COKAM:

For long workpieces two chucking fixations are necessary.

This workpiece feature (long) must be defined in terms of the workpiece model. Such a definition could be obtained through CECoS by having the expert assign this feature to the most general production class in the hierarchy. It is therefore suggested to apply COKAM before CECoS. Thereby the relevant features can be identified by COKAM and later defined through CECoS. CECoS is particularly suited for eliciting these abstraction rules (Egan \& Schwartz, 1979).

The pilot applications of the knowledge acquisition method also showed that COKAM reminds the expert of the relevant terms: when CECoS was performed after COKAM, the expert was more productive in generating good feature descriptions in CECoS.

\section{DISCUSSION}

When inference engines were extracted from the first successful expert systems (e.g. MYCIN) and applied in other domains, knowledge editing and knowledge elicitation tools proved to be useful. Knowledge acquisition was then tied to the structure of the inference engine, whereas the cognitive structures of human problem solving in the particular domain were ignored.

It was then believed that the knowledge acquisition problem would consist in uncovering unwieldy knowledge (e.g. implicit or compiled knowledge) which requires sophisticated elicitation and analysis methods (repertory grids, think aloud methods, interviewing techniques together with scaling techniques, protocol analysis, hierarchical cluster analysis). Different types of such elicitation and data analysis procedures were consequently combined to knowledge elicitation workbenches (e.g. Diederich, Linster \& Ruhmann \& Uthmann., 1987) so that a more complete knowledge collection would be established.

The success of these elicitation procedures has mainly been restricted to relatively small tasks where an expert system can be developed within a few hours (Boose, Bradshaw \& Kitto, 1989). Without a sophisticated model of expertise, however, such elicitation techniques can hardly be successfully applied to a complex task domain, such as production planning in mechanical engineering.

The limitations of bottom-up elicitation procedures can be overcome with the help of sophisticated models of expertise. The assumption that the knowledge acquisition problem consists in finding an appropriate model was very fruitful. Through an epistemological analysis of existing expert systems Clancey (1985) identified heuristic classification as the 
prevalent problem solving method in successful expert systems. Chrandrasekaran (1986) defined various generic tasks. In the KADS projects (Breuker \& Wielinga, 1989) a library of interpretation models is being developed (Breuker, Wielinga, van Someren, de Hoog, Schreiber, de Greef, Bredeweg, Wielemaker, Billaut, Davoodi, \& Hayward, 1987). Through such models, expert systems can be specified at the knowledge level (Newell, 1982; Clancey, 1989).

Such knowledge level descriptions of expert systems can be used to elicit exactly that knowledge which can be assimilated to the model so that the model together with the assimilated knowledge are sufficient for performing the target task. In order to develop a successful expert system, it must furthermore be warranted that appropriate traces of expertise and corresponding elicitation tools are available and accessible to the knowledge engineer.

Frequently, alternative models (e.g. opportunistic planning, case-based planning, skeletal plan refinement, etc.) are available for the same task. In these situations, that model may be selected which is cognitively most appropriate and for which supplementary traces of expertise are readily available. Knowledge elicitation and model building can thus be coordinated. This is accomplished by the HISOCO analysis: the cognitive analysis assists in specifying the best model of expertise and the sociological analysis reveals the most appropriate traces of expertise in the domain.

In the reported research, we have analyzed the complex task of production planning and established a knowledge level description for that task. The knowledge level description was obtained within the KADS framework. In KADS terminology, a task structure and an inference structure were established for production planning (Kühn, Schmalhofer \& Schmidt, 1990). The task structure states that each workpiece is first classified into some category that is associated with a skeletal plan. Supposedly the skeletal plan is appropriate for building a complete plan through refinement operations. In case of an inappropriate selection of a skeletal plan these procedures can be iterated. This task structure lead to the specification of the inference structure which was used as the model of expertise (see Figure 3 ). Because the inference structure provides the most detailed categorization of the domain knowledge, it was used for the knowledge acquisition rather than a complete interpretation model.

Since production planning is a very complex process, three additional domain categories (chucking, sequence of cutting operations and tool selection) were used in addition to the inference structure as orthogonal subdivisions to further modularize the knowledge elicitation. After an analysis of the available traces of expertise had been performed, two appropriate knowledge elicitation procedures were defined.

Through a coordinated knowledge elicitation from texts, previously solved cases, and expert memories, an early knowledge verification was accomplished by having the expert cognitively walk through the solved cases (Lewis, Polson, Wharton \& Rieman, 1990) by explaining them with the general information elicited from the other traces of expertise. This procedure should assist in developing knowledge bases for second generation experts systems which can explain their solutions (Swartout, 1983).

\subsection{COKAM and its Relation to Language Understanding}

COKAM requires the human user to perform a number of operations in a particular sequence. The operations and their sequence are similar to the cognitive processes which a human performs when he studies a text in order to extract specific task knowledge. In particular those text segments which appear to be relevant, are selected for further processing. After appropriate anaphora resolutions have been performed, the selected knowledge units can be assimilated to some prior knowledge structure until all slots of the knowledge structure are filled from the text, from hypotheses or through common sense. Text segments which fit into the prior knowledge structure are thus represented at an additional level (Schmalhofer \& Glavanov, 1986) and encounter a lot of processing while other text segments are relatively fast forgotten (Kintsch, Welsch, Schmalhofer \& Zimny, 
1990). COKAM thus utilizes results from research on human text comprehension (Kintsch, in press). A successful assimilation of natural language text into a knowledge structure may require many attempts which may produce several versions of the same text segment. Such processing can be performed with a previously developed tool. (Schmidt \& Wetter, 1989).

COKAM also shows a number of similarities to other knowledge acquisition methods from text (Anjewierden, Wiedemaker \& Toussaint, 1990, Möller, 1988; Szpakowicz, 1988; Jansen-Winkeln, 1988). The system of Szpakowicz for example supports semi-automated acquisition of structures from technical texts. It presumes an initial general model according to the KADS-method and then acquires conceptual structures from texts. The SHELLEY system of Anjewierden provides a hypertext-based protocol and concept editor, where the words of the stored text are mouse-sensitive, so that the definitions of the words can be inspected. Also, annotations are stored so that remarks from different people can be read on demand.

\subsection{CECoS for Retrieving Expert Memories}

Not every detail of a previously solved case is stored in human memory. Instead the human memory forgets the details and remembers the essential characteristics of a case. Contrary to human novices, who judge the similarity of two or more cases according to superficial features of the case, experts judge the similarity by the solution method which is applicable to the case (Chi, Feltovich \& Glaser, 1981). CECoS uses this fact to at first obtain an extensional definition of the various production classes for the particular cases used. Thereafter an intensional class definition is obtained by having the expert generate appropriate feature descriptions for each class. Since an intensional description can be applied for any case, it determines the class membership for any case. The knowledge elicitation of CECoS is thus also adjusted to the properties of human memory.

\subsection{Joint Application of both tools and integration aspects}

The joint application of COKAM and CECoS allows the integration of two traces of expertise which contain general information with a collection of specific cases (Rissland \& Skalak, 1989). Similar to humans who can learn from general statements and from specific examples by relating the general information to the specifics of the examples, both traces of expertise are used for the purpose of knowledge acquisition. This is accomplished by having the human expert explain the specific examples with the general information. This procedure has been shown to be quite useful for knowledge acquisition (Martin \& Redmond, 1989). The knowledge integration is thus similar to human knowledge integration, where the integration is performed through an assimilation to some preexisting model.

The elicitation of knowledge from multiple traces of expertise is also similar to KRITON (Linster, 1988) which consists of three tools, one used for protocol analysis, one used for interview analysis and a tool for text analysis. However there are also important differences: Whereas COKAM and CECoS provide a clearly defined procedure for combining the different knowledge sources, KRITON is open to all possible combinations. On the other hand, COKAM and CECoS are specifically tailored to a domain, where well thought through cases with their solutions as well as theoretical texts which relate to the cases are available. Contrary to knowledge engineering workbenches, which provide the knowledge engineer with tools but little guidance in how to use these tools, the proposed method supplies some machinery which guides the knowledge engineer and the expert to the desired expert system, while still providing him with enough freedom on which knowledge acquisition episode to perform next. Similar to the ontological analysis (Alexander, Freiling, Shulman, Rehfuss \& Messick, 1987) the proposed procedure thus provides a useful guideline to the knowledge engineer how to start the knowledge acquisition. This guideline has been particularly tailored to complex real world domains.

Eggen Lundteigen \& Mehus, (1990) have recently proposed a computational model for integration, where checking for completeness, correctness and consistency where described as the main objectives of the knowledge integration process. In the current method, these 
objectives are accomplished in two subsequent phases. In the explanation episode the relevance and completeness of the elicited knowledge are establish by having the expert give sufficient explanations for the various previously solved cases. A consistency and redundancy assessment is supported, by having the expert compare all knowledge units of the various categories. This is made feasible through a division of the set of knowledge units into sizeable categories.

\subsection{Case-Based Planning versus Skeletal Plan Refinement}

Since our model of expertise is skeletal plan refinement and not case-based planning, cases are only used as a vehicle in knowledge acquisition and are not themselves stored in the knowledge base. The proposed knowledge acquisition method may therefore be described as case-oriented: it uses cases to elicit knowledge from the expert memories and for testing the sufficiency of the general knowledge obtained from the text and the common sense rules expressed by the expert. This corresponds to the way in which experts often explain their knowledge. Contrary to case-based planning (Riesbeck \& Schank, 1989), where individual cases are appropriately indexed and then stored in a case-base, the knowledge base of the intended system would not contain any cases. Instead, the cases are only used during knowledge acquisition (Fox, J., Mypers, C. Greaves \& Pegram, 1985; Kidd, 1985) in order to find the relevant general knowledge units, which are sufficient to solve the target problems

\subsection{Early Verification versus Early Formalization}

The current research can be seen as an attempt to apply the KADS methodology to a highly complex application domain. Within this framework, we were successful in specifying an interpretation model, by adjusting the skeletal plan refinement model to the requirements of mechanical engineering. In particular the different available machining centers had to be taken into consideration. Recent research within the KADS-community is developing formal foundations and logical specifications for describing the conceptual model (Wetter, 1990). The approach of KADS II and related work, thus proposes to formalize models relatively soon, while the verification of the acquired knowledge is of less concern. In the current research, on the other hand, a formalization is proposed only after a verification and documentation of the acquired knowledge has been performed. Through early knowledge verification, relevance, sufficiency, redundancy and consistency may already be assessed with informally represented but model-centered knowledge.

In a complex domain, eliciting the relevant knowledge turns out to be a problem, even when a good model of expertise is found. With the described HISOCO analysis and the modelcentered knowledge acquisition method, we hope to master these challenges and to develop and easy to maintain knowledge-based system with good explanation capabilities in a real world domain. Similar to OPAL (Musen, Fagan, Combs, Shortliffe, 1987) the proposed method also is domain specific and uses skeletal plan refinement. It is different from OPAL in that it does not use as specific a domain model. Although the integrated knowledge acquisition method was developed for the domain of mechanical engineering, one may therefore expect that it could also be successfully applied in other domains.

\section{Acknowledgements}

We greatly appreciate the cooperation of our domain expert Dipl.-Ing. Ralf Legleitner and of our colleagues in the ARC-TEC project. Special thanks are due to Ralph Bergmann for his assistance in elaborating our ideas. 


\section{References}

Alexander, J.H., Freiling, M.J., Shulman, S.J., Rehfuss, S., and Messick, S.L. Ontological analysis: an ongoing experiment. International Journal of Man-Machine Studies 26 (1987), 473-485.

Anderson, J.R. The Architecture of Cognition, Harvard University Press, Cognitive Science Series (1983).

Anjewierden, A., Wielemaker, J., and Toussaint, C. Shelley - Computer Aided Knowledge Engineering. In Knowledge Acquisition via Knowledge Integration, Wielinga, B., Boose, J., Gaines, B., Schreiber, G., and van Someren, M., IOS Press, May 1990, pp. 41-59.

Bergmann, R.., Generierung von Skelettplänen als Problem der Wissensakquisition, Diplomarbeit Universität Kaiserslautern, 1990.

Bergmann, R. and Schmalhofer, F., CECoS: A Case Experience Combination System for Knowledge Acquisition for Expert Systems, Tech. Rept. Interner Bericht des ARC-TEC Projektes, German Research Center for Artificial Intelligence GmbH, 1990.

Boose, J.H. A Survey of Knowledge Acquisition Techniques and Tools. Knowledge Acquisition 1, (March 1989), 3-38.

Boose, J.H. and Bradshaw, J.M. Expertise transfer and complex problems: using AQUINAS as a knowledgeacquisition workbench for knowledge based systems. Int. Journal of Man-Machine Studies 26, (1987), 3-28.

Boose, J.H., Bradshaw, J., Kitto, C.M., and , Shema,D.B. From ETS to AQUINAS: Six Years of Knowledge Acquisition Tool Development. In Proceedings of the 4th Knowledge Acquisition for KnowledgeBased Systems Workshop, October 1-6 1989, pp. 5-1-5-17.

Boose, J.H. and Gaines, B.R. Knowledge Acquisition of Knowledge-Based Systems: Notes on the State-ofthe-Art. Machine Learning 4, 3/4 (December 1989), 377-394.

Brazdil, P.B. and Torgo, L. Knowledge Acquisition via Knowledge Integration. In Current Trends in Knowledge Acquisition, Wielinga, B., Boose, J., Gaines, B., Schreiber, G., and van Someren, M., IOS Press, May 1990, pp. 90-104.

Breuker, J. and Wielinga, B. Models of Expertise in Knowledge Acquisition. In Topics in Expert System Design, Methodologies and Tools. North-Holland, Guida, G. and Tasso, C., pp. 265 - 295 , Amsterdam, 1989.

Breuker, J., Wielinga, B., van Someren, M., de Hoog, R., Schreiber, G., de Greef, P., Bredeweg, B., Wielemaker, J., Billaut, J.P., Davoodi, M., and Hayward, S. Model-Driven Knowledge Acquisition: Interpretation Models. Tech. Rept. Esprit Project 1098, Deliverable Task A1, University of Amsterdam, Social Sciences Informatics, Amsterdam, 1987.

Brödner, P. Fabrik 2000, Rainer Bohn Verlag (1985).

Bullinger, H.J. and Salzer, C. Integration von CAD und CAP über ein gemeinsames Produktmodell. CIM Management 6 ,(1989).

Bylander, T. and Johnson, T.R. Structured Matching: A Task-Specific Technique For Making Decisions. In Proceedings of the 4th Knowledge Acquisition for Knowledge-Based Systems Workshop, October 1-6 1989, pp. 8-1-8-19.

Chandrasekaran, B. Generic Tasks in Knowledge-Based Reasoning: High-Level Building Blocks for Expert System Design. IEEE Expert (Fall 1986), 32 - 30.

Chase, W.G. and Ericcson, K.A. Skill and working memory. In The Psychology of learning and motivation. Academic Press, B., B., 1982.

Chi, M., Feltovich, P., and Glaser, R. Categorization and representation of physics problems by experts and novices. Cognitive Science 5 , (1981), 121-152.

Chien, S.A. Using and Refining Simplifications: Explanation-based Learning of Plans in Intractable Domains. In Proceedings of the Eleventh International Joint Conference on Artificial Intelligence, August 1989, pp. 590-595.

Clancey, W. Heuristic Classification. Artificial Intelligence 27(1985), 289 - 350.

Clancey, W.J. The Knowledge Level Reinterpreted: Modeling How Systems Interact. Machine Learning 4, 3/4 (December 1989), 285-291.

Diederich, J., Linster, M., Ruhmann, I., and Uthmann, T. A Methodology for Integrating Different Knowledge Elicitation Techniques. In Proceedings of EKAW87, Addis, T., Boose, J.H., and , Gains, B.R., University of Reading, 1987.

Egan, D.E. and Schwartz, B.J. Chunking in recall of symbolic drawings. Memory and Cognition 7 (1979), 149-158.

Eggen, J., Lundteigen, A.M., and Mehus, M. Integration of Knowledge from Different Knowledge Acquisition Tools. In Current Trends in Knowledge Acquisition, Wielinga, B., Boose, J., Gaines, B., Schreiber, G., and van S, M., IOS Press, May 1990, pp. 123-142.

Eversheim, W. Arbeitsvorbereitung. In Organisation in der Produktionstechnik. VDI Verlag, pp. 125-128, 1989.

Fandel G., Dyckhoff H. and Reese J. Industrielle Produktionsentwicklung, Springer-Verlag (1990)

Fischer, G., Lemke, A., and Mastaglio, T. Using Critics to Enpower Users. In CHI 1990 Conference Proceedings, 1990, pp. 337-347.

Fischer,U., Schmalhofer,F. Historische, Soziologische and Kognitive Aspekte der Fertigungstechnik. Tech. Rept. Interner Bericht des ARC-TEC Projektes, German Research Center for Artificial Intelligence GmbH, 1990.

Fox, J., Myers, C.D., Greaves, M.F., and Pegram, S. Knowledge Acquisition for Expert Systems: Experience in Lukemia Diagnosis. Methods of Information in Medicine 24 (1985), 65-72. 
Friedland, P.E. and Iwasaki, Y. The Concept and Implementation of Skeletal Plans. Journal of Automated Reasoning (1985), 161-208.

Gaines, B.R. Design Requirements For Knowledge Support Systems. In Proceedings of the 4th Knowledge Acquisition for Knowledge-Based Systems Workshop, October 1-6 1989, pp. 12-1-12-20.

de Groot, A.D. Perception and memory versus thought: some old ideas and recent findings. In Problem solving. Wiley, Kleinmuntz, B., 1966.

Hoffman,R. A Survey of Methods for Eliciting Knowledge of Experts. In: SIGART Newsletter 108,19-27, 1989.

Jacobson, C. and Freiling, M. Knowledge Dependencies. In Proceedings of the 4th Knowledge Acquisition for Knowledge-Based Systems Workshop, October 1-6 1989, pp. 16-1-16-19.

Jansen-Winkeln, R.M. Wastl: An Approach to Knowledge Acquisition in the Natural Language Domain. In Proceedings of the European Knowledge Acquisition Workshop (EKAW'88), June 19-23 1988, pp. 22-1-22-15.

Karbach, W., Linster, M., and Voß, A. Models of Problem-Solving: One Label - One Idea?. In Proceedings of EKAW90, Wielinga, B., Boose, J., Gaines, B., Schreiber, G., and van Someren, M., Universityof Amsterdam, IOS Press , Amsterdam, February 1990, pp. 173 - 189.

Kidd, A. Human Factors in the Design and Use of Expert Systems. In Fundamentals of Human-Computer Interaction. New York Academic Press, Monk, A., 1985

Kintsch,W., Welsch,D., Schmalhofer,F., Zimny,S. Sentence Memory: A Theoretical Analysis. In Journal of Memory and Language 29, 133-159 (1990).

Kintsch,W. How Readers Construct Situational Models for Stories: The Role of Syntactic Cues and Causal Inferences. In A.F.Healy, S.Kosslyn, \&R.M.Shiffrin (Eds.). Essays in honor of William K.Estes Hillsdale, NJ:Erlbaum (in press).

Kühn, O., Schmalhofer, F., and Schmidt, G. Diagnose von Wissenstypen für die Erstellung von Fertigungsplänen. Tech. Rept. Interner Bericht des ARC-TEC Projektes, German Research Center for Artificial Intelligence GmbH, 1990.

Lefkowitz, L.S. and Lesser, V.L. Knowledge Acquisition as Knowledge Assimilation. In 2nd AAAI Knowledge Acquisition for Knowledge-Based Systems Workshop, 1987.

Legleitner,R. Überlegungen zum Produktmodell von ARC-TEC. ARC-TEC Diskussionspapier 90-02, DFKI and Universität Kaiserslautern, FBK, 1990.

Lewandowsky, St., Dunn,J. \& Kirsner (eds) Implicit Memory: Theoretical Issues, Hilldsdale, Lawrence Erlbaum, 1989

Lewis, C., Polson, P., Wharton, C., and Rieman, J. Testing a Walkthrough Methodology for Theory-Based Design of Walk-Up-and-Use Interfaces. In Human Factors in Computing Systems (CHI '90 Conference Proceedings), Chew, J.C. and Whiteside, J., Addison-Wesley, April 1-5 1990, pp. 235 242.

Linster, M. A Critical Look at KRITON: Moving from First to Second Generation Expert Systems. In Proceedings of the 3rd Knowledge Acquisition Workshop, Boose, J.H. and Gaines, B.R., Banff, 1988, pp. $17.1-17.19$.

Martin, J. D. and Redmond M. Acquiring Knowledge by Explaining Observed Problem Solving. In Knowledge Acquisition: SIGART Newsletter 108 (April 1990), 77 - 83.

Möller, J.U. Knowledge Acquisition from Texts. In Proceedings of European Knowledge Acquisition Workshop (EKAW'88), 1988, pp. 25-1-25-16.

Mortik,K. Integration Issue in Knowledge Acquisition Systems. In SIGART Newsletter 108, 124-131, 1989.

Musen, M.A., Fagan, L.M., Combs, D.M., and Shortlife, E.H. Use of a domain-model to drive an interactive knowledge-editing tool. International Journal of Man-Machine Studies 26, (1987), 105 - 121.

Newell, A. The Knowledge Level. Artificial Intelligence 2(1982), 87 - 127.

Pfeiffer, J., Siepmann, T., and Teichmann, W. Expertensystem zur spanenden Bearbeitung. Tech. Rept. 2, Technische Mitteillungen Krupp, Krupp GmbH, 1988.

Richter, M., Boley, H., Wetter, T., and Warnecke, G. ARC-TEC: Acquisition, Representation and Compilation of Technical Knowledge. Tech. Rept. Projektantrag, German Research Center for Artificial Intelligence, Postfach 2080,D-6750 Kaiserslautern, 1989.

Richter,M.M. Expert Systems in mechanical engineering, In: UNISYS Symposium Expert Systems-A Management Perspective, Saint Paul de Vence, März 1990.

Riesbeck, C.K, Schank,R.C.. Inside case-based reasoning, Lawrence Earlbaum (1989).

Schmalhofer, F. and Wetter, T. Kognitive Modellierung: Menschliche Wissensrepräsentationen und Verarbeitungsstrategien. In Künstliche Intelligenz. Springer-Verlag, Christaller, T., Hein, H.W.W., and Richter, M.M., pp. 245-291, 1988.

Schmalhofer,F. and Glavanov, D. Three components of understanding a programmer's manual: Verbatim, propositional, and situational representations. In Journal of Memory and Language 25,279-294 (1986)

Schmalhofer,F. Expert Systems as Cognitive Tools for Human Decision Making. In: Mumpower,J.L., Lawrence,D.P., Renn,O., Uppuluri,V.R.R. (eds). Expert Judgment and Expert Systems 1987.

Schmidt, G., Legleitner, R., and Schmalhofer, F. Lautes Denken bei der Erstellung der Schnittaufteilung, der Werkzeugauswahl und Festlegung der Maschineneinstelldaten. Tech. Rept. Interner Bericht des ARC-TEC Projektes, German Research Center for Artificial Intelligence GmbH, 1990.

Schmidt, G. and Schmalhofer, F. Case-Oriented Knowledge Acquisition from Texts. In Current Trends in Knowledge Acquisition, Wielinga, B., Boose, J., Gaines, B., Schreiber, G., and van Someren, M., IOS Press, May 1990, pp. 302-312.

Schmidt, G. and Wetter, T. Towards Knowledge Acquisition in Natural Language Dialogue. In Proceedings of the Third European Workshop on Knowledge Acquisition for Knowledge-Based Systems (EKAW), 1989. 
Simon,H.A. The Science of the Artificial. The MIT Press; Cambridge, MA; 1981.

SPK-Feldmühle Werkzeuge, Examples for Application (Turning and Milling), Feldmühle AG, Produktbereich SPK-Werkzeuge, D-7333 Ebersbach a d.. Fils, Gottlieb-Häflel-Str. 7

Spur. Produktionstechnik im Wandel, Carl Hanser Verlag (1979).

Strube, G. and Janetzko, D. Episodisches Wissen und fallbasiertes Schließen: Aufgaben für Wissensdiagnostik und Wissenspsychologie. Schweizerische Zeitschrift für Psychologie (1990).

Swartout, W.R. XPLAIN: a System for Creating and Explaining Expert Consulting Programs. Artificial Intelligence 21 (1983), 285-325.

Szpakowicz, S. Semi-Automatic Acquisition of Conceptual Structure from Technical Texts. Workshop Banff (November 1988), 35-1-35-16.

Thien-Chien-Wysk-85a An Introduction to Automated Process Planning Systems, Prentice-Hall Inc. (1985)

Thoben,J., Schmalhofer,F. Wiederholungs- Varianten- und Neuplanung bei der Fertigung rotationssymmetrischer Teile. Tech. Rept. Interner Bericht des ARC-TEC Projektes, German Research Center for Artificial Intelligence GmbH, 1990.

Wachsmuth, I.,. On Structuring Domain-Specific Knowledge. LILOG-Report 12, IBM Deutschland GmbH 1987, P. O. Box 800880, D-7000 Stuttgart 80.

Weber, G. Cognitive diagnosis and episodic modelling in an intelligent LISP-tutor. In Proceedings of the International Conference on Intelligent Tutoring Systems, June 1988, pp. 207-214.

Wetter, T. First Order Logic Foundation of the KADS Conceptual Model. In Current Trends in Knowledge Acquisition, Wielinga, B., Boose, J., Gaines, B., Schreiber, G., and van Someren, M., IOS Press, May 1990, pp. 356-375.

Wielinga, B., Akkermans, H., Schreiber, G., and Balder, J. A Knowledge Acquisition Perspective on Knowledge-Level Models. In Proceedings of the 4th Knowledge Acquisition for Knowledge-Based Systems Workshop, October 1-6 1989, pp. 36-1-36-22.

Woodward, B. Knowledge Acquisition at the Front End: Defining the Domain. Knowledge Acquisition 2,1 (March 1990), 73 - 94. 


\section{DFKI Publikationen}

Die folgenden DFKI Veröffentlichungen sowie die aktuelle Liste von allen bisher erschienenen Publikationen können von der oben angegebenen Adresse oder per anonymem ftp von ftp.dfki.unikl.de (131.246.241.100) unter pub/Publications bezogen werden.

Die Berichte werden, wenn nicht anders gekennzeichnet, kostenlos abgegeben.

\section{DFKI Research Reports}

RR-92-43

Christoph Klauck, Jakob Mauss: A Heuristic driven Parser for Attributed Node Labeled Graph Grammars and its Application to Feature Recognition in CIM

17 pages

RR-92-44

Thomas Rist, Elisabeth André: Incorporating Graphics Design and Realization into the Multimodal Presentation System WIP 15 pages

\section{RR-92-45}

Elisabeth André, Thomas Rist: The Design of Illustrated Documents as a Planning Task 21 pages

\section{RR-92-46}

Elisabeth André, Wolfgang Finkler, Winfried Graf, Thomas Rist, Anne Schauder, Wolfgang Wahlster: WIP: The Automatic Synthesis of Multimodal Presentations

19 pages

\section{RR-92-47}

Frank Bomarius: A Multi-Agent Approach towards Modeling Urban Traffic Scenarios 24 pages

\section{RR-92-48}

Bernhard Nebel, Jana Koehler:

Plan Modifications versus Plan Generation:

A Complexity-Theoretic Perspective 15 pages

\section{RR-92-49}

Christoph Klauck, Ralf Legleitner, Ansgar Bernardi: Heuristic Classification for Automated CAPP 15 pages

\section{RR-92-50}

Stephan Busemann:

Generierung natürlicher Sprache

61 Seiten

\section{DFKI Publications}

The following DFKI publications or the list of all published papers so far are obtainable from the above address or per anonymous ftp from ftp.dfki.uni-kl.de (131.246.241.100) under pub/Publications.

The reports are distributed free of charge except if otherwise indicated.

\section{RR-92-51}

Hans-Jürgen Bürckert, Werner Nutt:

On Abduction and Answer Generation through Constrained Resolution

20 pages

\section{RR-92-52}

Mathias Bauer, Susanne Biundo, Dietmar Dengler, Jana Koehler, Gabriele Paul: PHI - A Logic-Based Tool for Intelligent Help Systems

14 pages

RR-92-53

Werner Stephan, Susanne Biundo:

A New Logical Framework for Deductive Planning 15 pages

\section{RR-92-54}

Harold Boley: A Direkt Semantic Characterization of RELFUN

30 pages

\section{RR-92-55}

John Nerbonne, Joachim Laubsch, Abdel Kader

Diagne, Stephan Oepen: Natural Language

Semantics and Compiler Technology

17 pages

\section{RR-92-56}

Armin Laux: Integrating a Modal Logic of Knowledge into Terminological Logics 34 pages

\section{RR-92-58}

Franz Baader, Bernhard Hollunder:

How to Prefer More Specific Defaults in

Terminological Default Logic

31 pages

\section{RR-92-59}

Karl Schlechta and David Makinson: On Principles and Problems of Defeasible Inheritance 13 pages

RR-92-60

Karl Schlechta: Defaults, Preorder Semantics and Circumscription

19 pages 
RR-93-02

Wolfgang Wahlster, Elisabeth André, Wolfgang Finkler, Hans-Jürgen Profitlich, Thomas Rist: Plan-based Integration of Natural Language and Graphics Generation

50 pages

\section{RR-93-03}

Franz Baader, Berhard Hollunder, Bernhard Nebel, Hans-Jürgen Profitlich, Enrico Franconi: An Empirical Analysis of Optimization Techniques for Terminological Representation Systems 28 pages

\section{RR-93-04}

Christoph Klauck, Johannes Schwagereit: GGD: Graph Grammar Developer for features in $\mathrm{CAD} / \mathrm{CAM}$

13 pages

RR-93-05

Franz Baader, Klaus Schulz: Combination Techniques and Decision Problems for Disunification 29 pages

\section{RR-93-06}

Hans-Jürgen Bürckert, Bernhard Hollunder, Armin Laux: On Skolemization in Constrained Logics

40 pages

RR-93-07

Hans-Jürgen Bürckert, Bernhard Hollunder, Armin Laux: Concept Logics with Function Symbols 36 pages

\section{RR-93-08}

Harold Boley, Philipp Hanschke, Knut Hinkelmann, Manfred Meyer: COLAB: A Hybrid Knowledge Representation and Compilation Laboratory 64 pages

\section{RR-93-09}

Philipp Hanschke, Jörg Würtz:

Satisfiability of the Smallest Binary Program 8 Seiten

RR-93-10

Martin Buchheit, Francesco M. Donini, Andrea Schaerf: Decidable Reasoning in Terminological Knowledge Representation Systems 35 pages

\section{RR-93-11}

Bernhard Nebel, Hans-Juergen Buerckert:

Reasoning about Temporal Relations:

A Maximal Tractable Subclass of Allen's Interval Algebra

28 pages

\section{RR-93-12}

Pierre Sablayrolles: A Two-Level Semantics for French Expressions of Motion 51 pages

\section{RR-93-13}

Franz Baader, Karl Schlechta:

A Semantics for Open Normal Defaults via a Modified Preferential Approach 25 pages

\section{RR-93-14}

Joachim Niehren, Andreas Podelski,Ralf Treinen: Equational and Membership Constraints for Infinite Trees

33 pages

\section{RR-93-15}

Frank Berger, Thomas Fehrle, Kristof Klöckner, Volker Schölles, Markus A. Thies, Wolfgang Wahlster: PLUS - Plan-based User Support

Final Project Report

33 pages

\section{RR-93-16}

Gert Smolka, Martin Henz, Jörg Würtz: ObjectOriented Concurrent Constraint Programming in $\mathrm{Oz}$

17 pages

\section{RR-93-17}

Rolf Backofen:

Regular Path Expressions in Feature Logic 37 pages

\section{RR-93-18}

Klaus Schild: Terminological Cycles and the Propositional $\mu$-Calculus

32 pages

\section{RR-93-20}

Franz Baader, Bernhard Hollunder: Embedding Defaults into Terminological Knowledge Representation Formalisms 34 pages

\section{RR-93-22}

Manfred Meyer, Jörg Müller:

Weak Looking-Ahead and its Application in Computer-Aided Process Planning 17 pages

RR-93-23

Andreas Dengel, Ottmar Lutzy:

Comparative Study of Connectionist Simulators 20 pages

\section{RR-93-24}

Rainer Hoch, Andreas Dengel:

Document Highlighting -

Message Classification in Printed Business Letters 17 pages

\section{RR-93-25}

Klaus Fischer, Norbert Kuhn: A DAI Approach to Modeling the Transportation Domain 93 pages

\section{RR-93-26}

Jörg P. Müller, Markus Pischel: The Agent Architecture InteRRaP: Concept and Application 99 pages

\section{RR-93-27}

Hans-Ulrich Krieger:

Derivation Without Lexical Rules 33 pages

\section{RR-93-28}

Hans-Ulrich Krieger, John Nerbonne, Hannes Pirker: Feature-Based Allomorphy 8 pages 
RR-93-29

Armin Laux: Representing Belief in Multi-Agent Worlds viaTerminological Logics

35 pages

RR-93-33

Bernhard Nebel, Jana Koehler:

Plan Reuse versus Plan Generation: A Theoretical and Empirical Analysis

33 pages

\section{RR-93-34}

Wolfgang Wahlster:

Verbmobil Translation of Face-To-Face Dialogs 10 pages

\section{RR-93-35}

Harold Boley, François Bry, Ulrich Geske (Eds.): Neuere Entwicklungen der deklarativen KI-

Programmierung — Proceedings

150 Seiten

Note: This document is available only for a nominal charge of 25 DM (or 15 US-\$).

\section{RR-93-36}

Michael M. Richter, Bernd Bachmann, Ansgar Bernardi, Christoph Klauck, Ralf Legleitner, Gabriele Schmidt: Von IDA bis IMCOD:

Expertensysteme im CIM-Umfeld

13 Seiten

RR-93-38

Stephan Baumann: Document Recognition of Printed Scores and Transformation into MIDI 24 pages

\section{RR-93-40}

Francesco M. Donini, Maurizio Lenzerini, Daniele Nardi, Werner Nutt, Andrea Schaerf:

Queries, Rules and Definitions as Epistemic

Statements in Concept Languages

23 pages

\section{RR-93-41}

Winfried H. Graf: LAYLAB: A Constraint-Based Layout Manager for Multimedia Presentations 9 pages

RR-93-42

Hubert Comon, Ralf Treinen:

The First-Order Theory of Lexicographic Path Orderings is Undecidable

9 pages

\section{RR-93-45}

Rainer Hoch: On Virtual Partitioning of Large Dictionaries for Contextual Post-Processing to Improve Character Recognition

21 pages

\section{DFKI Technical Memos}

\section{TM-91-14}

Rainer Bleisinger, Rainer Hoch, Andreas Dengel: ODA-based modeling for document analysis 14 pages

\section{TM-91-15}

Stefan Busemann: Prototypical Concept Formation An Alternative Approach to Knowledge Representation 28 pages

\section{TM-92-01}

Lijuan Zhang: Entwurf und Implementierung eines Compilers zur Transformation von

Werkstückrepräsentationen

34 Seiten

TM-92-02

Achim Schupeta: Organizing Communication and Introspection in a Multi-Agent Blocksworld 32 pages

TM-92-03

Mona Singh:

A Cognitiv Analysis of Event Structure

21 pages

\section{TM-92-04}

Jürgen Müller, Jörg Müller, Markus Pischel, Ralf Scheidhauer:

On the Representation of Temporal Knowledge 61 pages

\section{TM-92-05}

Franz Schmalhofer, Christoph Globig, Jörg Thoben: The refitting of plans by a human expert 10 pages

TM-92-06

Otto Kühn, Franz Schmalhofer: Hierarchical skeletal plan refinement: Task- and inference structures 14 pages

\section{TM-92-08}

Anne Kilger: Realization of Tree Adjoining Grammars with Unification 27 pages

\section{TM-93-01}

Otto Kühn, Andreas Birk: Reconstructive Integrated Explanation of Lathe Production Plans 20 pages

\section{TM-93-02}

Pierre Sablayrolles, Achim Schupeta: Conlfict Resolving Negotiation for COoperative Schedule Management 21 pages

\section{TM-93-03}

Harold Boley, Ulrich Buhrmann, Christof Kremer: Konzeption einer deklarativen Wissensbasis über recyclingrelevante Materialien 11 pages 


\section{DFKI Documents}

D-92-19

Stefan Dittrich, Rainer Hoch: Automatische,

Deskriptor-basierte Unterstützung der Dokumentanalyse zur Fokussierung und Klassifizierung von Geschäftsbriefen

107 Seiten

D-92-21

Anne Schauder: Incremental Syntactic Generation of Natural Language with Tree Adjoining

Grammars

57 pages

D-92-22

Werner Stein: Indexing Principles for Relational Languages Applied to PROLOG Code Generation 80 pages

D-92-23

Michael Herfert: Parsen und Generieren der Prolog-artigen Syntax von RELFUN 51 Seiten

\section{D-92-24}

Jürgen Müller, Donald Steiner (Hrsg.):

Kooperierende Agenten

78 Seiten

\section{D-92-25}

Martin Buchheit: Klassische Kommunikations- und Koordinationsmodelle

31 Seiten

D-92-26

Enno Tolzmann:

Realisierung eines Werkzeugauswahlmoduls mit Hilfe des Constraint-Systems CONTAX 28 Seiten

D-92-27

Martin Harm, Knut Hinkelmann, Thomas Labisch: Integrating Top-down and Bottom-up Reasoning in COLAB

40 pages

D-92-28

Klaus-Peter Gores, Rainer Bleisinger: Ein Modell zur Repräsentation von Nachrichtentypen 56 Seiten

\section{D-93-01}

Philipp Hanschke, Thom Frühwirth: Terminological Reasoning with Constraint Handling Rules 12 pages

\section{D-93-02}

Gabriele Schmidt, Frank Peters,

Gernod Laufkötter: User Manual of COKAM+ 23 pages

\section{D-93-03}

Stephan Busemann, Karin Harbusch(Eds.):

DFKI Workshop on Natural Language Systems: Reusability and Modularity - Proceedings 74 pages

\section{D-93-04}

DFKI Wissenschaftlich-Technischer Jahresbericht 1992

194 Seiten

\section{D-93-05}

Elisabeth André, Winfried Graf, Jochen Heinsohn, Bernhard Nebel, Hans-Jürgen Profitlich, Thomas Rist, Wolfgang Wahlster:

PPP: Personalized Plan-Based Presenter 70 pages

D-93-06

Jürgen Müller (Hrsg.):

Beiträge zum Gründungsworkshop der

Fachgruppe Verteilte Künstliche Intelligenz Saarbrücken 29.-30. April 1993

235 Seiten

Note: This document is available only for a nominal charge of 25 DM (or 15 US-\$).

D-93-07

Klaus-Peter Gores, Rainer Bleisinger:

Ein erwartungsgesteuerter Koordinator zur partiellen Textanalyse

53 Seiten

\section{D-93-08}

Thomas Kieninger, Rainer Hoch: Ein Generator mit Anfragesystem für strukturierte Wörterbücher zur Unterstützung von Texterkennung und Textanalyse 125 Seiten

\section{D-93-09}

Hans-Ulrich Krieger, Ulrich Schäfer:

TDL ExtraLight User's Guide

35 pages

D-93-10

Elizabeth Hinkelman, Markus Vonerden,Christoph Jung: Natural Language Software Registry

(Second Edition)

174 pages

\section{D-93-11}

Knut Hinkelmann, Armin Laux (Eds.):

DFKI Workshop on Knowledge Representation Techniques - Proceedings

88 pages

\section{D-93-12}

Harold Boley, Klaus Elsbernd, Michael Herfert, Michael Sintek, Werner Stein:

RELFUN Guide: Programming with Relations and Functions Made Easy

86 pages

D-93-14

Manfred Meyer (Ed.): Constraint Processing Proceedings of the International Workshop at CSAM'93, July 20-21, 1993

264 pages

Note: This document is available only for a nominal charge of 25 DM (or 15 US-\$). 